\title{
Direct closure of the septum primum in atrioventricular canal defects
}

\author{
René Prêtre, $\mathrm{MD}^{\mathrm{a}}$ \\ Hitendu Dave, $\mathrm{MD}^{\mathrm{a}}$ \\ Alexander Kadner, $\mathrm{MD}^{\mathrm{a}}$ \\ Dominique Bettex, $\mathrm{MD}^{\mathrm{b}}$ \\ Marko I. Turina, $\mathrm{MD}^{\mathrm{a}}$
}

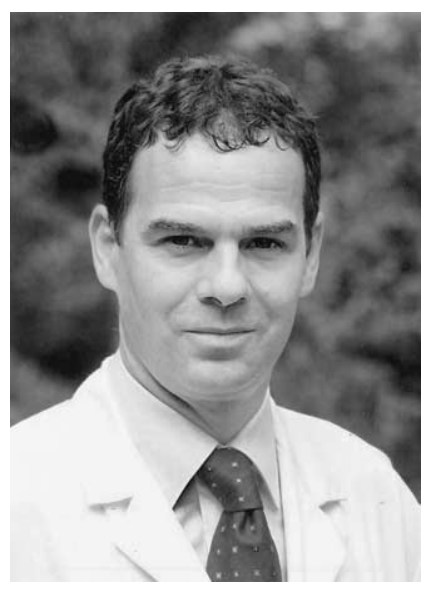

Dr Prêtre
Objective: The objective of this study was to assess the safety of directly closing the septum primum during the correction of atrioventricular canal defects.

Methods: We performed a retrospective analysis of our experience with direct closure of the septum primum during the repair of atrioventricular canal defect. The series consisted of 28 consecutive patients presenting with a partial (15 patients) and complete (13 patients) atrioventricular canal defect. The cleft in the atrioventricular valve was closed completely in 25 patients and partially in 3 patients (those with a small left lateral leaflet). In complete atrioventricular canal, the ventricular septum defect was closed with a patch of polytetrafluoroethylene (Gore-Tex, W. L. Gore \& Associates, Inc, Flagstaff, Ariz) or xenopericardium. Follow-up was complete and ranged from 3 to 21 months (median 11 months).

Results: There were no early or late deaths and no surgical complications. The septum primum defect was closed completely in all patients as assessed by echocardiography. All the patients were in sinus rhythmus, and none had even a temporary complete atrioventricular block. The surgical result and heart rhythm have remained stable over time.

Conclusions: Direct closure of the septum primum is an easy, quick, and safe procedure during repair of atrioventricular defects.

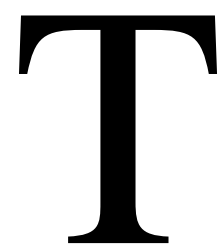

he defect of the septum primum is a landmark of atrioventricular (AV) canal defects. ${ }^{1}$ Closure of the defect is usually performed with a patch of autologous pericardium. ${ }^{2-4}$ The patch must be correctly shaped and cautiously inserted along the coronary sinus to avoid obstruction of the coronary blood flow or a heart block. To avoid these risks, a few surgeons insert the patch around the coronary From the Departments of Cardiovascular
Surgery $^{\mathrm{a}}$ and Anesthesia, ${ }^{\mathrm{b}}$ University Hospital Zurich, Zurich, Switzerland.

Received for publication Aug 20, 2003; revisions requested Sept 26, 2003; accepted for publication Oct 7, 2003.

Address for reprints: René Prêtre, MD, Clinic for Cardiovascular Surgery, University Hospital Zurich, Ramistrasse 100, Zurich, CH-8091 Switzerland (E-mail: rene.pretre@usz.ch).

J Thorac Cardiovasc Surg 2004;127: 1678-81

$0022-5223 / \$ 30.00$

Copyright (C) 2004 by The American Association for Thoracic Surgery

doi:10.1016/j.jtcvs.2003.10.030 sinus, which is then left to drain in the left atrium. Although an increase in left atrial pressure (as may occur in a left AV valve insufficiency) can theoretically hinder coronary perfusion, severe myocardial ischemia has never been reported in these instances. In case of drainage of a persistent left superior vena cava in the sinus coronarius, the orifice of the coronary sinus must be set in the right atrium to avoid a right-left shunt of blood.

We present here a reliable, simple, and quick technique to close a septum primum defect that always sets the orifice of the coronary sinus in the right atrium and that does not seem to bear a particular risk of disturbing the function of the conducting tissues.

\section{Materials and Methods}

All of the patients who underwent operation for a complete or partial AV canal since October 2001 (the date when we started to directly close the septum primum) were included. There 
were 28 patients presenting with partial (15 patients) and complete (13 patients) AV defects. Demographic and clinical data are summarized in Table 1. Transesopheal echocardiography was performed in all patients to assess the repair during operation. Two patients with a relative ventricular imbalance caused by a small left ventricle underwent fenestration of the septum secundum. All of the patients were examined by their cardiologists or at our clinic 3 months after the operation with transthoracic echocardiography. Follow-up information regarding clinical status and echocardiographic findings were obtained in all patients. Follow-up time ranged from 3 to 21 months (median 11 months).

\section{Baseline Correction}

The operation was performed under cardiopulmonary bypass and mild hypothermia, with intermittent antegrade cold blood cardioplegia. The cardiac defect was approached through right atriotomy. The closure of the ventricular septum defect in complete AV canal and the reconstruction of the AV valve were performed according to our usual technique. The ventricular septal defect was corrected with a patch tailored to exactly cover the defect. The bridging leaflets were separated along a line corresponding to the plane of the right side of the ventricular septum. A polytetrafluoroethylene (0.4 mm in thickness; Gore-Tex, W. L. Gore \& Associates, Inc, Flagstaff, Ariz) or xenopericardium patch was inserted on the right side of the border of the ventricular septum defect with a continuous suture of a nonresorbable suture. The severed bridging leaflets of both AV valves were reinserted on the free border of the patch with the same continuous suture. The cleft on both AV valves was closed with a continuous suture of resorbable suture. In 3 patients with a small left lateral leaflet, the cleft was only partially closed to avoid valvular stenosis. These valves were tri-foliated. A partial posterior annuloplasty was performed if a residual leak was present on water instillation in the left ventricle, as previously described. ${ }^{5}$ When the reconstruction of the AV valves was judged adequate, the septum primum was closed with a continuous suture of resorbable material.

\section{Closure of the Septum Primum}

A 7-0 Maxon (United States Surgical Corporation, Norwalk, Conn) or polydioxanone (Ethicon, Inc, Somerville, NJ) suture was used for this purpose for children aged less than 3 years of age and a 6-0 suture was used for those aged more than 3 years. The border of the septum primum was gently grasped with a forceps and brought along the AV valves. By doing so, one was able to precisely define the point where the suturing should start in the inferior part of the defect. There, only a superficial bite was taken and the suture was tied. The 2 or 3 subsequent bites remained very superficial, 1 on the border of the septal defect and 1 on the inferior AV valve leaflet (Figure 1). The insertion of the septum followed a curved line until it reached (after 4-5 bites) the line of readaptation of the bridging leaflets. Once the septum reached this line (the AV valve annulus in partial AV canal and the border of the VSD patch in complete AV canal), bigger bites could be taken without risking an injury to the conducting tissue. The entire septum primum was closed with a single layer of running suture. Additional defects on the atrial septum, especially on the septum secundum, were also directly closed with a running suture of
TABLE 1. Demographic and clinical data

\begin{tabular}{lcc}
\hline & $\begin{array}{c}\text { Complete } \\
\text { AV canal } \\
\text { (n= 13) }\end{array}$ & $\begin{array}{c}\text { Partial } \\
\text { AV canal } \\
\text { (n = 15) }\end{array}$ \\
\hline Male/female & $2 / 11$ & $6 / 9$ \\
Age (median) & $4,5 \mathrm{mo}$ & $3,8 \mathrm{y}$ \\
Sternotomy/right & $13 / 0$ & $6 / 9$ \\
$\quad$ lateral thoracotomy & & \\
Aortic crossclamp & $69 \mathrm{~min}$ & $40 \mathrm{~min}$ \\
$\quad$ time (median/range) & $(58-90)$ & $(32-64)$ \\
CPB time & $121 \mathrm{~min}$ & $95 \mathrm{~min}$ \\
$\quad$ (median/range) & $(105-141)$ & $(70-120)$
\end{tabular}

$A V$, Atrioventricular; $C P B$, Cardiopulmonary bypass.

resorbable material. The rest of the operation was performed in the usual manner.

\section{Results}

All patients resumed sinus rhythm within a few minutes after release of the aortic crossclamp. Transesophageal echocardiography showed a successful correction with complete closure of the atrial septum defect in all patients. Atrial morphology appeared to be totally normal (Figure 2), in contrast with the bulging of the patch observed previously. The repair of the AV valves was adequate in all patients, with no more than mild left AV valve insufficiency. In fact, 24 patients had no or only trace left AV valve insufficiency, and 3 patients had mild insufficiency. No patients died, and none had serious postoperative complications. Five children with complete AV canal showed transient pulmonary hypertension or hypertensive crisis that was controlled with inhaled nitric oxide. The repair remained stable in all patients, as assessed by subsequent transthoracic echocardiography. They all remained in sinus rhythm.

\section{Discussion}

Direct closure of a septum primum defect seems possible without an excessive risk of creating an AV block. In the literature, the risk of a complete AV block after patch repair of the septum primum ranges from $3 \%$ to $5 \% .^{6,7}$ We have not encountered this complication in a consecutive series of 28 patients. All the patients were in sinus rhythm by the end of the operation, and the rhythm remained stable during the follow-up period. These facts are reassuring regarding the safety of this technique. The fact that the pressure difference between the 2 atria does not exceed a few millimeters of mercury allows the use of a fine suture and superficial so-called endocardial bites around the Koch triangle. The inferior border of the atrial septum defect is not sutured on the plane separating both AV valves, but on the inferior leaflet of the left AV valve below the plane of leaflet separation. This does not interfere with the left AV valve motion because this part of the AV valve, in direct relation 


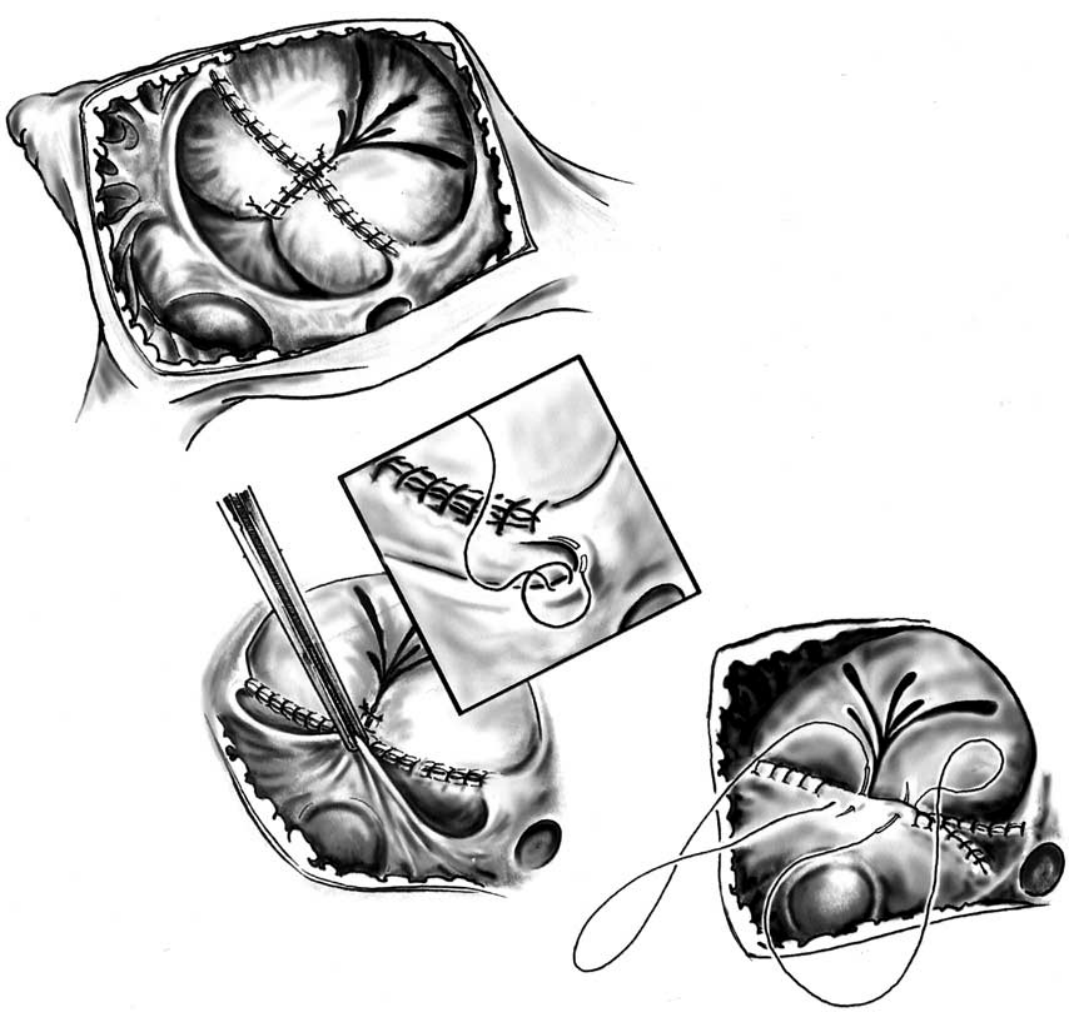

Figure 1. Direct closure of a septum primum defect in a complete AV canal defect. Note the curved line of insertion of the atrial septum along the inferior bridging leaflet. Superficial so-called endocardial bites are taken in the inferior part of the defect.
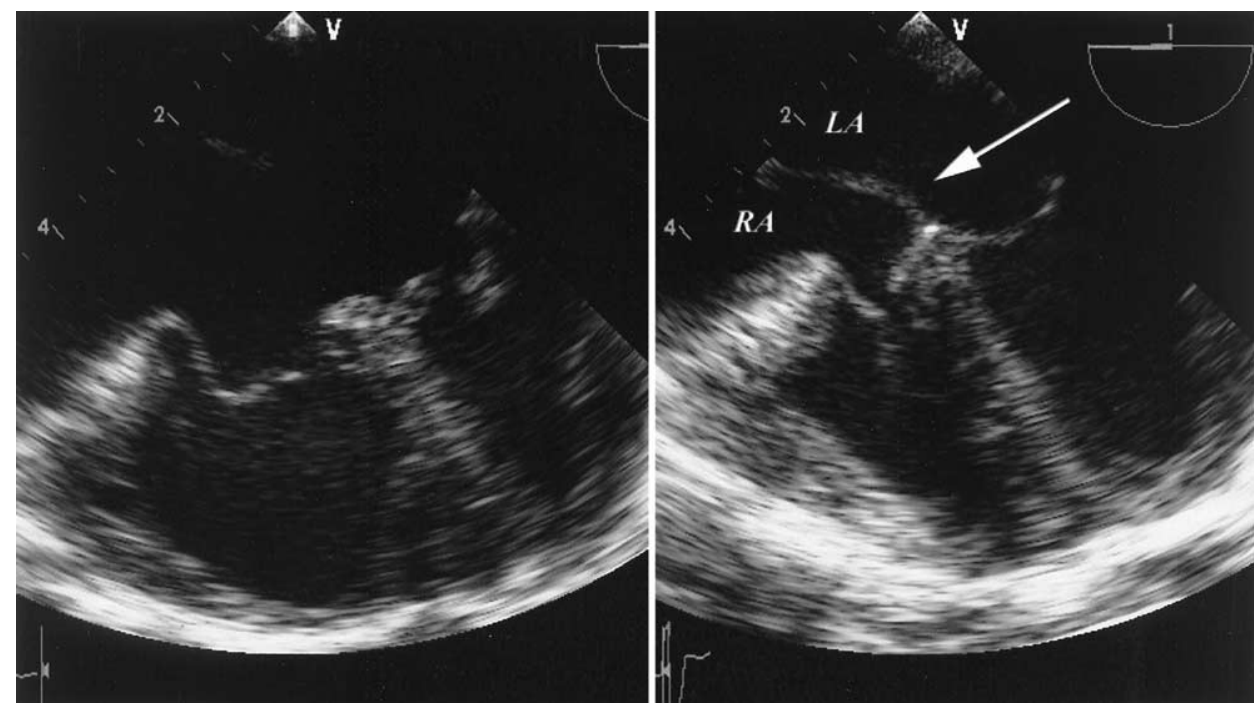

Figure 2. Transesophageal echocardiography after correction of a partial AV canal. Note the normal appearance of the atrial septum. $L A$, Left atrium, $R A$, right atrium. Arrow indicates the closure of the septum primum defect.

with the Koch triangle, shows minimal motion during heart cycles. Although the inferior part of the defect closure must be performed very cautiously, the entire septum primum can usually be closed within a few minutes, more rapidly than after the use of a pericardial patch. This also results in a small reduction of the size of the atrium (in contrast with the 
use of a patch, which increases the size), which is possibly an advantage in dilated atria.

Although some surgeons have recommended the use of a patch to close large septum defects, ${ }^{8}$ we have been able to apply the direct closure technique in all our cases, regardless of the size of the septum primum defect and of the size and number of additional atrial septum defects (which were also closed directly in this series). It is our routine practice to use resorbable sutures on living tissues, and we have not seen a suture loosening over time. The same closure can, however, be performed with a nonresorbable suture.

The echocardiographic control that we routinely performed during operation showed an atrial septum without evidence of a residual shunt of blood and with apparently normal atria. The left AV valve never showed more than a mild insufficiency. All our patients resumed a sinus rhythm within a few minutes after release of the aortic crossclamp, indicating a safe technique regarding the occurrence of an AV block. These findings remained stable over time.

The simplicity of the defect closure, the restoration of a more normal atrial dimension, and the safety regarding preservation of the AV conduction make the technique attractive in both partial and complete AV canal defects.

\section{References}

1. Jacobs JP, Burke RP, Quintessenza JA, Mavroudis C. Congenital Heart Surgery Nomenclature and Database Project: atrioventricular canal defect. Ann Thorac Surg. 2000;69(4 Suppl):S36-43.

2. Alexi Meskishvili V, Ishino K, Dahnert I, Uhlemann F, Weng Y, Lange $\mathrm{PE}$, et al. Correction of complete atrioventricular septal defects with the double-patch technique and cleft closure. Ann Thorac Surg. 1996;62:519-24.

3. Backer CL, Mavroudis C, Alboliras ET, Zales VR. Repair of complete atrioventricular canal defects: results with the two-patch technique. Ann Thorac Surg. 1995;60:530-7.

4. Hanley FL, Fenton KN, Jonas RA, Mayer JE, Cook NR, Wernovsky G, et al. Surgical repair of complete atrioventricular canal defects in infancy. Twenty-year trends. J Thorac Cardiovasc Surg. 1993;106:387-94.

5. Prêtre R, Kadner A, Dave H, Bettex D, Turina MI. Overlapping annuloplasty of the mitral valve in children. Ann Thorac Surg. (in press).

6. Mavroudis C, Backer CL. The two-patch technique for complete atrioventricular canal. Semin Thorac Cardiovasc Surg. 1997;9:35-43.

7. Alexi Meskishvili V, Hetzer R, Dahnert I, Weng Y, Lange PE. Results of left atrioventricular valve reconstruction after previous correction of atrioventricular septal defects. Eur J Cardiothorac Surg. 1997;12: 460-5.

8. Chikada M, Sekiguchi A, Miyamoto T, Matsuzaki M, Ishida R, Ishizawa A. Direct closure of ostium primum defect in the repair of atrioventricular septal defect. Ann Thorac Surg. 2001;72:430-2.

\section{Authoritative}

The Journal of Thoracic and Cardiovascular Surgery is the most frequently cited thoracic/cardiovascular surgery journal in the Science Citation Index. An article in JTCVS is cited on average almost twice as often as those in the closest cardiothoracic journal. 